\section{MODERN SYSTEMS OF INDEPENDENT LIGHTING AND HEATING.}

(I) Oil, Oil Gas, and Petrol-air Gas Systems.

UNTIL quite a late period in the nineteenth century country houses were invariably lighted either by candles or oil lamps. To-day there are at our disposal many different systems of lighting, suited respectively to the cottage and the mansion.

For small houses in remote districts there is still a good deal to be said for the paraffin or petroleum lamp, provided a well-constructed and trustworthy type is employed, and the oil used is of a good standard quality. At the present time lamps giving as much as 100 candle-power can be obtained, and in favourable circumstances $300-500$ candle-power hours, or even more, can be obtained per gallon of oil. The fact that the oil lamp is entirely self-contained and can readily be moved from place to place is naturally an advantage, and the low intrinsic brilliancy of the

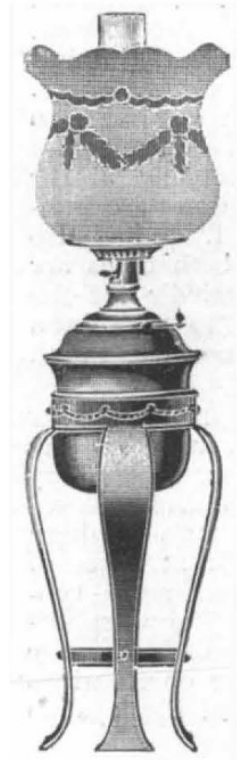

FIG. x.-."Petrolite" lamp using upright incandescent mantle fed by air which has passed through porous material impregnated with vola. tile bydrocarbons. flame and the mellow colour of the light are considered pleasing by many people.

The type of shade used with the oil lamp is of some importance. The vertical shallow tin reflectors attached to cheap forms of paraffin lamps are not very satisfactory. Such lamps are sometimes hung on the walls, throwing out the light into the room indiscriminately and giving a somewhat glaring effect. It is preferable to use some form of diffusing glass shade completely screening the light from the eyes and directing the rays downward to the table. The oil lamp is probably at its best when equipped with such a shade, and used in a central position in the room, or immediately above the surface it is intended to illuminate.

The introduction of incandescent oil lamps (i.e. lamps using oil or paraffin vapour with an incandescent mantle) led to a great increase in efficiency. There are now many such lamps on the market. For example, the Petrolite lamp, in which air is sucked through a porous material impregnated with suitable hydrocarbons, a draught being secured by using an exceptionally long chimney. The lamp is claimed to be exceptionally safe, as it goes out at once if accidentally upset. According to some recent tests a light of 40 candles can be obtained by burning $1 \frac{1}{2} \mathrm{oz}$. of hydrocarbon per hour.

The incandescent oil system, however, gives the most efficient results when used for relatively powerful lighting units. A well-known type is the Blanchard lamp, using paraffin vapour, with an inverted mantle. These lamps range in illuminating power from roo to 1500 candles, and are claimed to give more than 10,000 candle-hours per gallon of oil. Their use is very simple, and the evolution of vapour can be easily started with a little spirit. Amongst other lamps of this type we may mention the Kitson, Still, and Petromax lamps, all of which are capable of giving a high candle-power, and are particularly useful for lighting large rooms, country halls, yards, etc., or for fêtes and garden parties.

The illuminants mentioned above are all self-contained and portable, and are cheap and simple in No. 2410 , VOL. 96] operation. On the other hand, they naturally require a little attention, so that in larger residences the trouble involved in looking after a large number of lamps in different rooms is worth consideration. Hence there has sprung up a demand for a distributing system, similar to gas and electricity, and available in localities where these methods of lighting are not available. The "petrol-air gas plants," of which there are now a number of types on the market, were designed to satisfy this need.

Petrol-air gas consists simply of air to which has been added a small percentage of petrol vapour. Such a mixture is very easily produced owing to the volatile nature of petrol, and can be generated by a small automatic plant, conveniently kept in a small outhouse. The mixture generated is then led into the house through pipes and distributed to incandescent

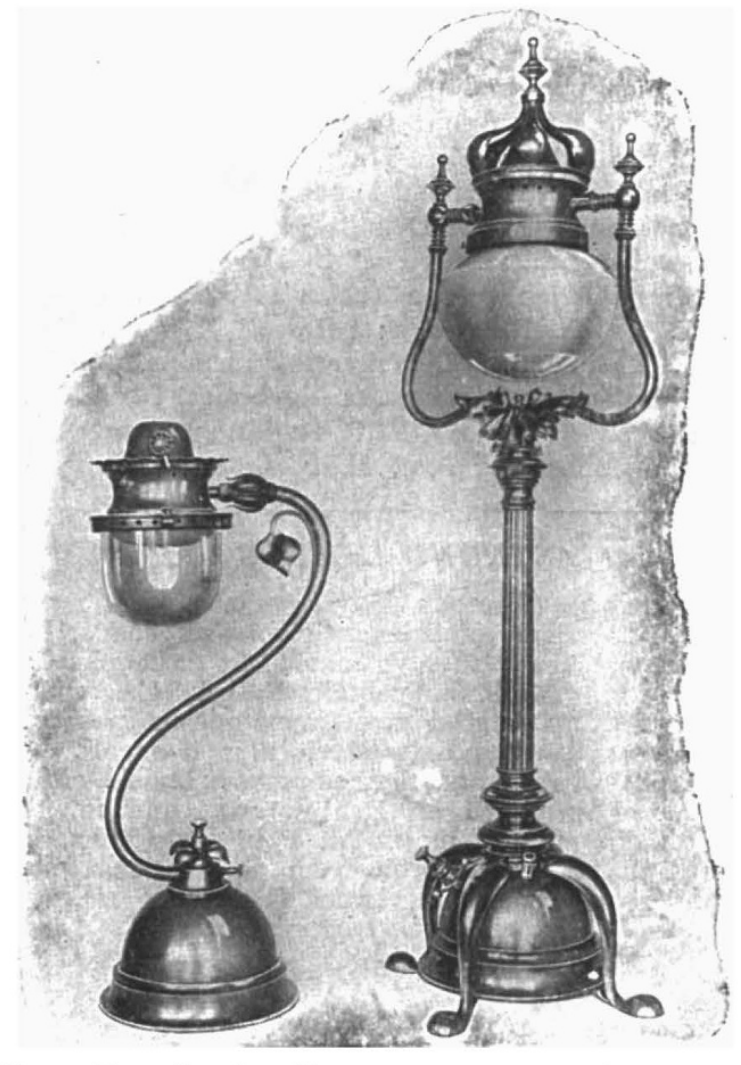

FIG. 2.-Types of small candle-power portable Blanchard incandescent oil lamps. With this system units from 100 to I 500 c.p. can be obtaineu.

burners in the same way as coal-gas. (This gas can only be used with mantles, and is not suitable for burning in flat flame burners.) The percentage of petrol employed is invariably small (2-6 per cent., according to the system). The gas has only a slight and not unpleasant smell. Owing to the large amount of air carried into the burner through the pipes the vitiation of the air is small, and, as there should be no objectionable impurities, the system is also clean and hygienic. In view of the small amount of petrol vapour used, the system is also claimed to be safe, and it is said that even a leak would not, in ordinary circumstances, give rise to any danger of fire or explosion. It is, however, essential that the consumer should purchase a trustworthy type of machine. In some of the earlier plants the composition of the mixture was apt to vary according to the load and 
the temperature of the air, and there was even a tendency for petrol to condense in the pipes during cold weather. These defects should not exist in any trustworthy type of modern machine.

The chief elements in a petrolair gas plant are the carburetter, in which the desired mixture of petrol and air is produced; the holder in which the gas is stored; and the compressor for the purpose of driving the gas through the pipes. The motive power may be supplied by a falling weight, hot-air engine, or water power. For country-house lighting, the falling weight is usually preferred on account of its simplicity. A trustworthy plant should operate quite automatically, yielding the same quality of gas, however many lights are turned on (within the limits of the plant), and should require little or no attention beyond filling up with petrol when necessary and occasionally winding up the weight.

A technical point of some interest is the percentage of petrol which it is desirable to include in the gas. In some cases, for example in the "County" petrol-air gas system, the comparatively rich mixture of 6 per cent. is preferred, and it is considered that this enables the plant to be designed and operated on highly scientific lines, and that it is of value in enabling a mixture of

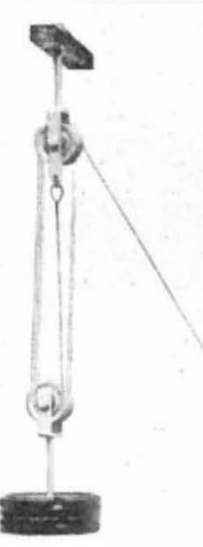

stated to operate quite satisfactorily, and it is also claimed that ordinary motorcar petrol can be used, and that no special variety of lighting spirit is required.

A petrol-air gas system enables lights to be installed permanently in position and used either as central or units or wall brackets. The ordinary type of inverted burner used is of the Bijou type, from which as much as 7o-8o candle-power may be obtained with No. 24 Io, vol. 96] percentage of pet rol is 2 per cent. only. This is

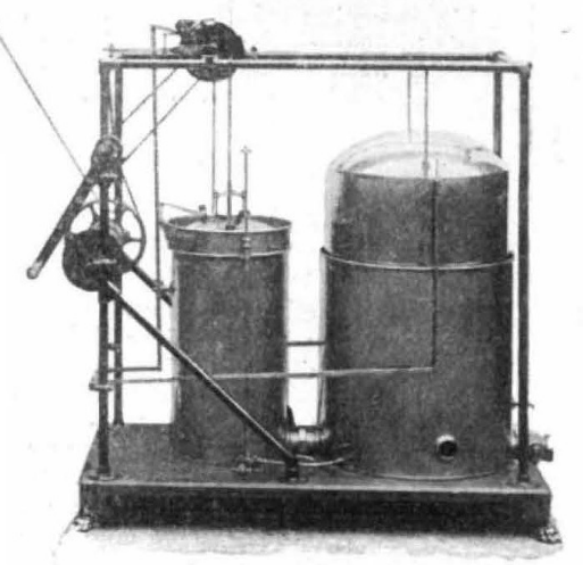

FIf. 3.-General view of "County" petrol-air gas plant. new mantles. In favourable circumstances 100-120 of these lights can be run for a consumption of one gallon of petrol per hour. A small plant, feeding

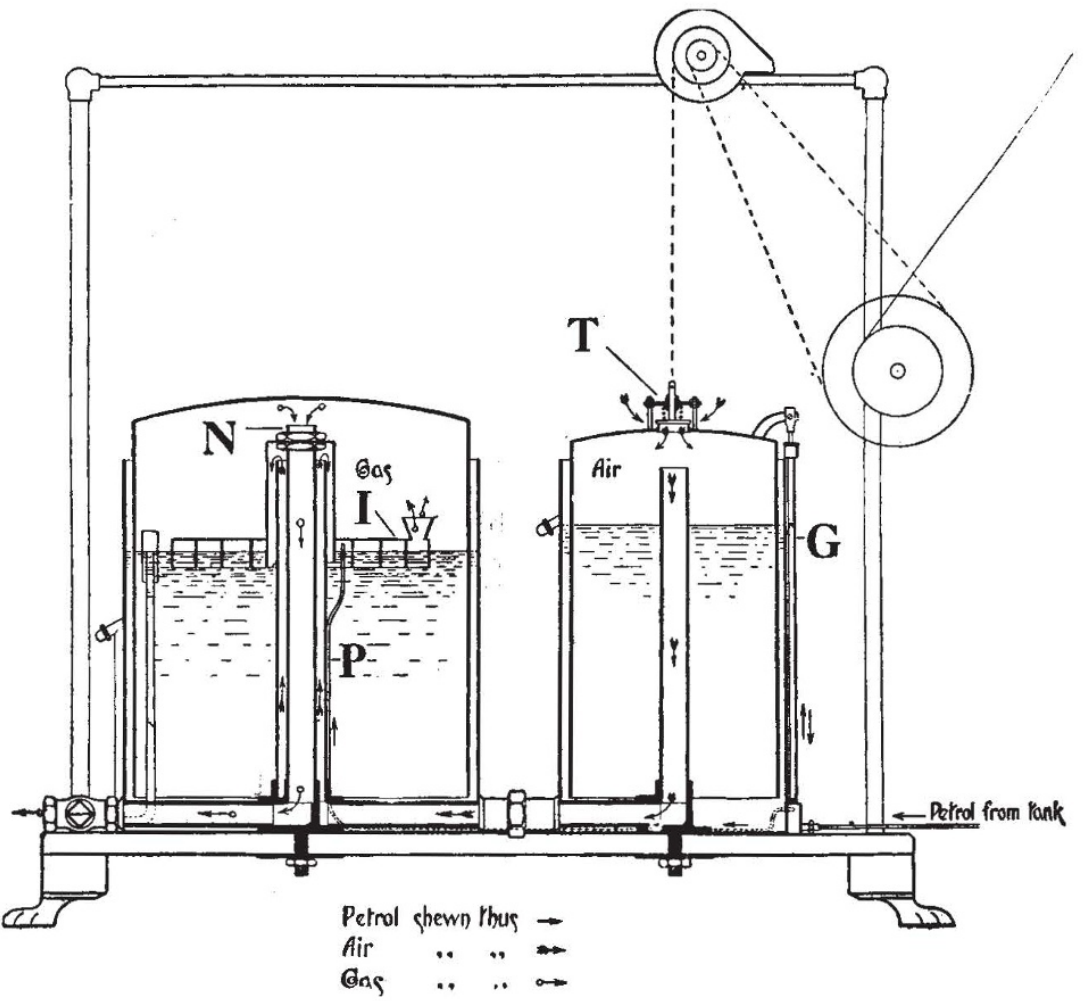

FIG. $3 a$.-Sectional view of "County" petrol-air gas plant. In this diagram three types of arrows are used to denote the respective paths taken by the air, petrol, and the resulting gas. The plant consists in the main of two ccpper bells working in water seals, the smaller of which acts as an air pump whilst the larger constitutes the holder for the gas as it is made. The air-pumping bell is made to rise and fall by means of the weights and on its upstroke takes in air through the valve $T$. On reaching the top of its stroke it is disengaged from the action of the weights (which are then held stationary), and the valve $T$ closing, the air-bell falls by its own weight and drives air down the central pipe $K$ into the larger bell via the pipe $\mathrm{L}$ and the annuius $\mathrm{F}$. Before reaching the larger bell, however, it is caused to pass close along the surface of the carburetter by the baffle plate $I$. The petrol is delivered on to the surface of the carburetter by the petrol pump $G$ in small amounts (a teaspoonful or so at a time) along the small pipe $\mathbf{P}$. The petrol pump $\mathrm{G}$, being attached directly to the air-bell, makes stroke for stroke with it, thus ensuring that air is never delivered without its complement of petrol under any conditions of running. The gas is delivered to the service down the central pipe at $\mathbf{N}$.
IO-20 lights, would probably cost about $25 l .-35 l$. A larger size, capable of supplying roo lights, about Iool.-12ol. The complete cost of lighting installation, including plant, piping, and simple fixtures, would probably work out to between two and three times the above figures. Much, however, depends on the expenditure on fittings and the shed for housing the plant, and the distance from which materials have to be supplied. Prices have naturally been affected somewhat by the war. A consumer should remember that in remote places it is not always easy to get prompt technical assistance, and should therefore be careful to select a thoroughly up-to-date and trustworthy make of machine, even if somewhat more expensive than others on the market.

The above remarks have referred mainly to the use of petrol-air gas plants for country houses, but there are also opportunities for its use in small workshops, laboratories, etc. It has also been used occasionally for military camps and even for village lighting, I in such cases the nature of the area to be covered has an important bearing on the method of illumination supplied. In a large and scattered area the 
question will arise whether it is worth while to run mains from the nearest gas or electrical supply; or whether it is not more economical, for a temporary installation, to rely exclusively on portable illuminants such as those described in the earlier portion of the article, and to avoid the use of piping altogether.

The fact that petrol-air gas can be readily applied for heating is also an advantage, especially in laboratories where bunsen burners and small heating appliances are much used. In country houses petrol-air gas may also be used for small cooking ranges, the usual size of which consumes an amount of petrol equivalent to about twenty lights. Stoves for use in the fireplace to heat rooms can also be supplied, but as a rule the small householder finds it preferable to use a coal or wood fire rather than incur the expense of installing the exceptionally large plant necessary to heat a number of rooms.

There remain to be mentioned the systems of light-

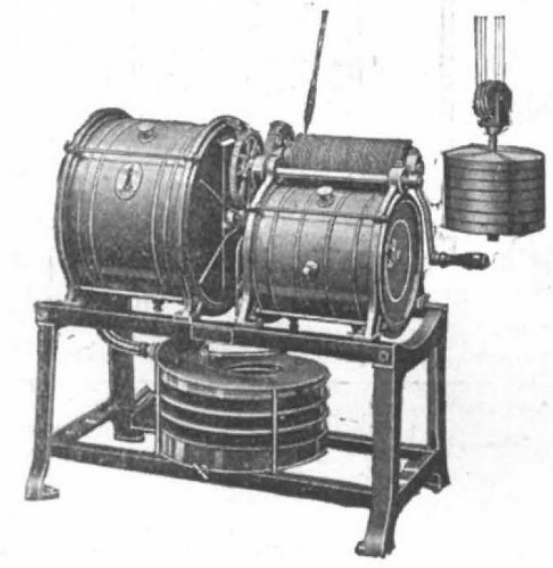

Fig. 4.-General view of Willett petrol-air gas plant. The plant consists of three chief parts-air compressor, petrol container, and spiral carburetter. The air compressor contains a cylindrical drum having in it a number of "scoops" so shaped as to produce a series of helical channels; the lower portion of the drum is filled with water. The petrol drum contains a number of small cups attached to the ends of rods which are fixed to revolving spindle. These cups discharge their contents into a funnelshaped receptacle, which in turn is controlled by the petrol regulator. Both the scoops in the air compressor and the spindle carrying the cups in the petrol drum are actuated by the suspended weight and work in perfect uniformity. The helical scoops in revolving take quantity of air which is helical scoops in revolving take up a measured tank at the air which is compressed and dischargen into a rectaneular tank at the side, from whence it passes into the carburetter. Meantime the carburetter receives a regulated amount of petrol in the manne described. The inter-connection of the apparatus for supplying air and petrol maintains the correct proportions of these constituents: no holde is needed to store the gas which is generated as required, the machine

ing and heating which generate gas from heavy oils, fats, etc., which require heat for distillation. These systems are claimed to be highly economical on a large scale, and are usually employed for large buildings, institutions, factories, country railway stations, etc. Many railways make their own oil gas, which is compressed and used for carriage lighting.

The Mansfield oil gas producer is widely used for generating this quality of gas, and is claimed to be applicable to a wide variety of fuels, such as creosote, palm oil, kerosene, and even tallow and unrefined fat. The oil is stored in a suitable tank and guided in a fine stream into a retort heated by a wood or coal fire. In this way a permanent oil gas is produced which, after purification, is stored in a holder and supplied through pipes in the usual way. The gas produced may be used either with incandescent mantles or in a flat flame burner. It may aIso be used for heating, having a high calorific power. In NO. 24 IO, VOL. 96] some cases a portion of the gas is used for cooking and heating water, and the remainder is utilised to drive an engine and dynamo, furnishing electric light. A system of this kind naturally requires some attention, but is claimed to be capable of being worked by unskilled labour, and to be very simple in operation.

\section{RESEARCHES ON SPRUE.1}

$\mathrm{SPRUE}$ is a disease of chronic course, the main features of which are a frothy diarrhœa generally accompanied by a sore tongue; the disease as it progresses producing severe anæmia and exhaustion. The word sprue in English medical literature was first used by Manson in 1880 , and is apparently the anglicised form of the Dutch spruw. One would like to know something of the origin of this Dutch word. The form sproo was also used in the year 1825 in Scotland for "a disease affecting the mouth of very young children." This disease is in all probability the same as thrush, and it is important to note in this connection that the condition of the tongue in thrush is similar to that in sprue. The word thrush, the origin of which is obscure, is not known before the seventeenth century, when Pepys speaks of "a fever, a thrush, and a hickup." It may also be mentioned that sprue in Scotland was the term used for "that which is thrown off in casting metals" (scoria).

The present work deals with the disease in Ceylon, where "Ceylon sore mouth" is one of the names for the disease. There are no figures available to show its frequency in Europeans or in the natives in the island, but that it does occur in the latter in various countries appears to be fairly certain. It is apparently also a disease determined by long residence in the tropics, though on all these points one speaks with hesitation as accurate data are not available. That dysentery is a common predisposing cause there appears to be no doubt, but whether there is any other closer connection between the two diseases is doubtful.

A sore tongue is one of the features of sprue, and microscopically the epithelium is found to be desquamating. This dead epithelium is infiltrated with yeasts, and in some cases the yeast threads appear to be actually invading the living cells. This is not, however, found to be the case in the stomach or gut, which are also inflamed, though the gut contents contain masses of yeast, and yeasts are the commonest organisms in motions passed shortly before death. This infection of the gut contents with yeasts does not, however, occur in other wasting diseases, the author very properly having made adequate control observations. Yeasts, then, not only can be cultivated from the majority of sprue stools and salivas, but in the acute stage they are the most prevalent organisms in the tongue lesions, saliva. and motions.

Now thrush, a common disease of infants in temperate climates, is generally believed to be due to yeasts, and in some respects-e.g. atrophy of the tongue epithelium-resembles sprue. The author, indeed, inclines to the view that yeasts are in fact the cause of the disease. One might object, however, that if this were so one would expect sprue to be a far commoner disease than it is, as yeasts in the tropics are ubiquitous. The view held by some authors that it has affinities to scurvy is an "attractive" one, and is supported by the beneficial effect of a fruit diet such as strawberries or bael fruit. This work is an interesting record of a careful research, valuable although inconclusive in its results. The plate of

"A Report on Researches on Sprue in Ceylon, rgre-r4." By Dr. P. H. 7s. $6 d$. net. 